$$
\begin{aligned}
& \text { ANL/CHM/OP93338 } \\
& \text { CONF-970962 - }
\end{aligned}
$$

Symposium Proceedings: Progress in Metal Ion Separation and Preconcentration

\author{
Chapter XX
}

\title{
Extraction Chromatography: Progress and Opportunities
}

\author{
RECENED \\ NOV 041997 \\ Mark L. Dietz, E. Philip Horwitz, and Andrew H. Bond \\ OSFI
}

Chemistry Division, Argonne National Laboratory,

9700 S. Cass Ave., Argonne, IL 60439

MRETER

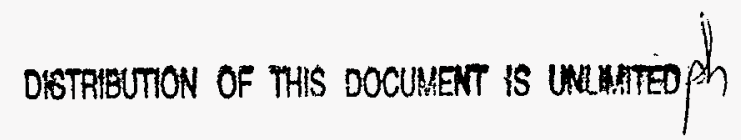

\begin{abstract}
Extraction chromatography provides a simple and effective method for the analytical and preparative-scale separation of a variety of metal ions. Recent advances in extractant design, particularly the development of extractants capable of metal ion recognition or of strong complex formation in highly acidic media, have significantly improved the utility of the technique. Advances in support design, most notably the introduction of functionalized supports to enhance metal ion retention, promise to yield further improvements. Column instability remains a significant obstacle, however, to the process-scale application of extraction chromatography.
\end{abstract}

Extraction chromatography (EXC) is a type of liquid-liquid chromatography that couples the selectivity of solvent extraction $(l)$ with the multistage character of a

The submitted manuscript has been created by the University of Chicago as Operator of Argonne National Laboratory ("Argonne") under Contract No. W-31-109-ENG-38 with

the U.S. Departent of Energy. The wis

the U.S. Department of Energy. The U.S.

Government retains for itself, and others act-

ing on its behall, a pald-up, nonexclusive,

irrevocable worldwide license in said anticle

to reproduce, prepare derivative works, dis-

tribute copies to the public, and perform pub-

licly and display publicly, by or on behalf of 


\section{DISCLAIMER}

This report was prepared as an account of work sponsored by an agency of the United States Government. Neither the United States Government nor any agency thereof, nor any of their employees, makes any warranty, express or implied, or assumes any legal liability or responsibility for the accuracy, completeness, or usefulness of any information, apparatus, product, or process disclosed, or represents that its use would not infringe privately owned rights. Reference herein to any specific commercial product, process, or service by trade name, trademark, manufacturer, or otherwise does not necessarily constitute or imply its endorsement, recommendation, or favoring by the United States Government or any agency thereof. The views and opinions of authors expressed herein do not necessarily state or reflect those of the United States Government or any agency thereof. 


\section{DISCLAMIER}

Portions of this docament may be illegible in electronic image products. Images are produced from the best available original docomentert. 
chromatographic process and the ease of handling associated with ion-exchange resins (2). Typically, extraction chromatographic materials are prepared by simple immobilization (i.e., adsorption) of an organic extractant onto any of a wide variety of inorganic (e.g., alumina, silica) or organic (e.g., cellulose, styrene-divinylbenzene copolymers) supports. In contrast to ordinary partition chromatography, in which the partitioning solute undergoes little, if any, chemical change, the sorption of a metal ion in EXC involves the complex chemical changes associated with the conversion of a hydrated metal ion into a neutral organophilic metal complex, just as in liquid-liquid extraction. This conversion often involves a number of interactions and equilibria, manipulation of which affords opportunities for the design of systems capable of the efficient and selective separations of a variety of metal ions (3).

Since its introduction by Siekierski in 1959 (4), extraction chromatography has been studied extensively, and a number of reviews $(5,0)$ and monographs ( 7 ) have appeared summarizing various aspects of the technique. In this chapter, we examine recent progress in this field, with particular emphasis on work directed at improving the performance of extraction chromatographic materials and broadening their range of applications.

\section{Background}

Conventional extraction chromatographic materials are prepared by the physical impregnation of an inert substrate with either an undiluted extractant or a solution of the extractant in an appropriate diluent. This impregnation can be accomplished by any of a variety of techniques (5-7). Most commonly, a porous support material is contacted with a solution of the extractant or of an extractant-diluent mixture in a volatile solvent, and the solvent slowly removed by evaporation under vacuum. Alternatively, the support is contacted with a solution of the extractant in a mixture of an organic solvent and water, the support separated from the solution by filtration, and the excess organic solvent removed by water washing. For very hydrophobic 
extractants, the most satisfactory results (i.e., homogeneous impregnation of the support) have been obtained by contacting a solution of the extractant in a precalculated amount of solvent with a support until all of the liquid has been absorbed. Because none of these methods is particularly well-suited to the preparation of large quantities of EXC materials, procedures have been devised by which the extractant can be incorporated directly into the support during its preparation. The Levextrel resins $(8,9)$, for example, are macroporous styrenedivinylbenzene copolymers containing an extractant added to the mixture of monomers during the polymerization process. By appropriate choice of reaction conditions, the amount of extractant incorporated, the extent of cross linking of the polymer, and other resin characteristics (e.g., porosity, surface area) can be varied as desired (10). Although in principle this approach could be applied with any extractant, in actual practice, only certain types of extractants (e.g., neutral organophosphorus extractants, aliphatic amines) have appropriate physical and chemical properties (e.g., viscosity, solubility, acidity) for inclusion, as the polymerization process is affected by the extractant properties (9).

Regardless of the method by which an EXC material is prepared, the immobilization of the extractant on the support is the result of physical interactions, not covalent bond formation between the extractant and the support. For certain EXC materials, most notably those employing a polymeric support, the nature of these interactions have been the subject of considerable interest. In a recent series of studies by Cortina et al. (11-13), for example, the adsorption of various acidic organophosphorus extractants (e.g., di-(2-ethylhexyl)phosphoric acid, HDEHP) on Amberlite XAD-2 (a non-polar macroporous styrenic polymer) was examined using FT IR. Comparison of the infrared spectrum of supported HDEHP to that of the free extractant in carbon tetrachloride showed that adsorption is accompanied by only small shifts in both the phosphoryl $(\mathrm{P}=\mathrm{O})$ and $\mathrm{P}-\mathrm{O}-\mathrm{C}$ stretching bands of the extractant and in the various stretching frequencies (e.g., normal modes of methyl and methylene units) associated with Amberlite XAD-2. This indicates that the 
interaction between the extractant and support is quite weak, consisting of only the attractive forces between alkyl chains and/or aromatic rings of the ligand and those of the support. Much the same can be said of the interactions of other extractants studied with the same or related supports (e.g., polyesters) (13-15). Thus, in most instances, the immobilization of an extractant on a support is the result of a combination of weak adsorption and/or physical entrapment of the extractant.

Given the absence of significant interactions between the extractant and support in conventional EXC materials, the complexation properties of a supported extractant would be expected to closely parallel those of the same extractant in a liquid-liquid system. In fact, qualitatively, this is what is generally observed. Recently, the behavior of several extractants supported on various substrates has been examined quantitatively by treating EXC materials as an extractant homogeneously dispersed in a solid matrix and applying equilibrium models developed originally for liquid-liquid systems in which an extractant is homogeneously dispersed in an organic solvent. Kimura (10), for example, studied the uptake of Th(IV) and U(VI) by tri- $n$-butyl phosphate (TBP)-loaded Amberlite XAD-4, a high surface area macroporous styrenedivinylbenzene copolymer. Measurements of the extractant, acid, and nitrate dependencies of the sorption of the two cations by the resin were found to be consistent with the extraction of $\mathrm{Th}\left(\mathrm{NO}_{3}\right)_{4} \cdot 2 \mathrm{TBP}$ and $\mathrm{UO}_{2}\left(\mathrm{NO}_{3}\right)_{2} \cdot 2 \mathrm{TBP}$, respectively, in agreement with solvent extraction data. In effect then, XAD-4 functions as an inert diluent for the TBP (16). In more recent work, Cortina et al. (12) examined the sorption of $\mathrm{Zn}(\mathrm{II}), \mathrm{Cu}(\mathrm{II})$, and $\mathrm{Cd}(\mathrm{II})$ from nitrate solutions by HDEHPloaded Amberlite XAD-2. Treatment of the $\mathrm{pH}$ and extractant dependence of $\log \mathrm{D}$ (where $\mathrm{D}$ is defined as $[\mathrm{M}]_{\mathrm{resin}} /[\mathrm{M}]_{\mathrm{aq}}$ ) using Letagrop-distr indicated that the nature of the metal species extracted is somewhat different than that reported for extraction of the same metals into toluene $(\mathrm{Zn})(17)$ or paraffinic hydrocarbons $(\mathrm{Cu}, \mathrm{Cd})(18$ 21 ), with the extracted species in the EXC system typically less solvated than in the organic solvents. In addition, it was observed that the extractant, which exists largely as a dimer in non-polar solvents, is less associated in the support. Also, it was found 
that while the extractability of zinc, copper, and cadmium into organic solvents by HDEHP follows the order $\mathrm{Zn}>\mathrm{Cu}>\mathrm{Cd}$, for the supported reagent, cadmium extraction exceeds that of copper. Other recent work by Strikovsky et al. (22), which examined copper extraction by the sulfur analog of HDEHP, di(2ethylhexyl)dithiophosphoric acid (DEHTPA), supported on Amberlite XAD-2, however, found that the extraction equilibria/constant correspond well with liquidliquid extraction results in $n$-heptane. Taken together, the results of these and other related studies (23) suggest that for many EXC materials, quantitative predictions of metal ion retention properties from liquid-liquid extraction data are feasible. Nonetheless, in certain instances, even a relatively inert support can have unanticipated effects on the physicochemical properties of an extractant.

Many aspects of the performance of an extraction chromatographic resin are not readily predictable from liquid-liquid extraction data, as far more factors are involved in a dynamic chromatographic process than in batch (i.e., static) liquid-liquid extraction (24). The performance of an extraction chromatographic material is normally defined in terms of seven parameters: retention, selectivity, efficiency, capacity, stability (physical and chemical), ease of regeneration, and reproducibility/repeatability. Like retention, the selectivity of a given EXC material is governed primarily by the nature of the extractant and the composition of the mobile phase. The selectivity of a given chromatographic system can, however, also be altered by the presence of macrolevels of retained elements, by impurities in the extractant, and by the presence of active sites on the support material.

As with all chromatographic processes, column efficiency is of considerable importance in EXC, since excessive band spreading (i.e., poor column efficiency) can render the separation of two metals difficult or impossible, even if the extractant comprising the stationary phase exhibits very high selectivity for one of the ions. Column efficiency is generally expressed in terms of height equivalent to a theoretical plate (HETP) or simply, plate height $(\mathrm{H})$, and is a complex function of a number of system characteristics. In EXC systems, efficiency is determined primarily by three 
factors: flow phenomena, diffusion in the stationary phase, and extraction kinetics (25). The contribution to the plate height due to flow phenomena is given by the following equation:

$$
H=\Sigma\left(\frac{1}{2} \lambda_{i} d_{p}+\frac{D_{M}}{\omega_{i} d_{p}^{2} v}\right)^{-1}
$$

where $\lambda_{i}$ and $\omega_{i}$ are parameters related to the bed structure and velocity inequalities of the mobile phase in the interstitial space, $d_{p}$ is the diameter of the support particle, $D_{M}$ is the diffusion coefficient of the ion in the mobile phase, and $v$ is the interstitial mobile phase velocity. The contribution to the plate height arising from stationary phase diffusion is given by equation 2 :

$$
H=q \cdot \frac{k^{\prime}}{\left(1+k^{\prime}\right)^{2}} \cdot \frac{d_{l}^{2} v}{D_{S}}
$$

where $q$ is a configuration factor which depends on the shape of the stationary phase, $\mathrm{k}^{\prime}$ is the capacity factor (the number of free column volumes to the peak maximum), $d_{j}$ is the depth of the stationary phase, and $D_{S}$ is the diffusion coefficient of the metal ion-extractant complex in the stationary phase. Finally, the band spreading resulting from extraction kinetics is given by the equation:

$$
\mathrm{H}=\frac{2 \mathrm{k}^{\prime}}{\left(1+\mathrm{k}^{\prime}\right)^{2}} \cdot \frac{\mathrm{v}}{\mathrm{k}_{\mathrm{oa}}}
$$

where $\mathrm{k}_{\mathrm{oa}}$ is the first-order rate constant for the extraction of the solute ion from the stationary phase into the mobile phase. The relative contributions of each of these three factors to column efficiency depends on the specific chemical system, the particle size and porosity of the support, the operating temperature, the extractant loading, and the mobile phase flow velocity. The predominant factor for a particular 
EXC system can be determined by measuring the plate height as a function of mobile phase flow velocity for materials of various particle sizes and extractant loadings at several temperatures (25). This type of study, although essential in obtaining a full understanding of the parameters governing band broadening in a given EXC system, has only rarely been carried out.

Since extraction chromatography has most frequently been applied in analyticalscale separations (vide infra), the capacity of EXC materials has typically been regarded as being of secondary importance. In preparative or process-scale applications, however, capacity can become an important consideration. The maximum capacity of an EXC material for a particular metal ion will depend on the total amount of extractant that can be loaded onto the support. This, in turn, is dependent on the nature of the support. Clearly, to maintain a given capacity, the extractant loaded onto the support must be satisfactorily retained; that is, the EXC material must exhibit adequate physical stability. Given the absence of strong interactions between the extractant and the support in a typical extraction chromatographic material, it is not surprising that loss of extractant into the eluent is often cited as the major limitation of EXC. Although loss of extractant can sometimes be minimized by careful control of eluent composition (e.g., $\mathrm{pH}$ ) or by presaturation of the mobile phase with extractant, these are not always viable options.

Although most compounds employed as stationary phases in EXC have been selected on the basis of prior satisfactory application in liquid-liquid extraction, and are thus expected to have adequate chemical stability, the possibility of chemical degradation of the extractant during use must also be considered. Taken together, it is the physical and chemical stability of a particular EXC system that determines the feasibility of its regeneration, as well as the reproducibility of the results obtained upon repeated use of a given column. 


\section{Recent Developments}

Extractants. Recent advances in molecular design and synthetic methodology have led to a wide array of new extractants, among them crown ethers (26), cryptands (27), calixarenes (28), and bifunctional organophosphorus reagents capable of stronger and more selective binding of a target ion (particularly in acidic media) than many of the extractants traditionally employed in EXC (e.g., TBP, HDEHP). The availability of such extractants has led to the development of extraction chromatographic sorbents exhibiting strong, and often, quite selective retention of a number of metal ions from aqueous solution. The effect of improved extractants on the performance of EXC materials is especially evident in the development of EXC methods for the separation and preconcentration of the radionuclides ${ }^{241} \mathrm{Am}$ and ${ }^{90} \mathrm{Sr}$ from environmental and biological matrices and nuclear waste samples for subsequent determination.

The development of such methods for ${ }^{90} \mathrm{Sr}$ separation and preconcentration is complicated by two factors. First, a number of procedures for the determination of radionuclides in biological or environmental samples (e.g., urine, feces (29), soil (30)) involve a preliminary digestion or leaching of the sample with acid, producing a final sample solution often several molar in nitric acid. Thus, any proposed separation method should be effective for highly acidic samples. Strontium sorption from acidic media (i.e., mineral acid solutions) is further complicated by the chemistry of the ion itself. That is, because of its large ionic radius and low charge, Sr(II) has a relatively low charge density. As a result, the energy associated with bond formation between it and the functional groups of many organic extractants is insufficient to completely dehydrate both the cation and the anions that must accompany the strontium into the organic (stationary) phase to maintain electrical neutrality. Thus, sorption of strontium from acidic media requires the transfer of a complex bearing a number of associated water molecules into an organic phase. As would be expected, the net result is generally very poor strontium extraction. 
During the 1960's and 1970's, several extraction chromatographic systems were devised for the separation of strontium from other alkaline earth cations or from various other elements (31-34). All of these systems, however, suffered from serious shortcomings, among them insufficient selectivity over calcium, inadequate retention of strontium (particularly from solutions containing high concentrations of mineral acids), and the need for cumbersome sample treatment. Recent work by two of the authors (MLD and EPH) has shown that the use of a crown ether-based extraction chromatographic material can provide a means of overcoming all of the limitations associated with previous EXC systems (35-37). Crown ethers possess a macrocyclic ring whose dimensions can be tailored to provide a good fit for the cation of interest, thereby yielding selective complexation. Earlier work directed at the development of methods for the removal and recovery of strontium- 90 from nuclear waste streams led to a process known as SREX (for $\underline{\text { S }}$ Rontium EXtraction), capable of selectively extracting strontium from solutions containing even high ( $\geq 3 \mathrm{M}$ ) concentrations of nitric acid:

$$
\mathrm{Sr}^{2+}(\mathrm{aq})+\mathrm{NO}_{3}-(\mathrm{aq})+\overline{\text { Crown Ether }} \rightleftharpoons \overline{\left.\mathrm{Sr}\left(\mathrm{NO}_{3}\right)_{2} \text { (Crown Ether }\right)}
$$

The process solvent used, which consists of a $0.2 \mathrm{M}$ solution of bis-4, 4' (5')-[tertbutylcyclohexano]-18-crown-6 (Figure 1a) in 1-octanol, provides a solution to the charge density problem (noted above) by combining the crown ether with a solvent capable of dissolving a substantial amount of water (38-40). In such a system, extraction involves the transfer of the strontium/crown ether complex from aqueous solution into a water-like, yet water-immiscible, organic medium. The result is greatly improved extraction efficiency. In subsequent work (35-37), it was shown that impregnation of an inert polymeric support (e.g., Amberlite XAD-7) with a $1 \mathrm{M}$ solution of this same crown ether in 1-octanol yields an extraction chromatographic resin that retains all of the favorable properties (e.g., strontium selectivity) of the corresponding liquid-liquid system. 
Figure 2 shows the nitric acid dependency of the uptake of alkali and alkaline earth cations (expressed as $k$ ', the number of free column volumes to the maximum of the elution band) by the new resin ( $\mathrm{Sr}$ resin). As can be seen, strontium is well retained at acid concentrations exceeding $\sim 2 \mathrm{M}$. Under these same conditions, barium is the only other alkali or alkaline earth cation that exhibits appreciable sorption. Barium interference is easily dealt with, however, by loading the sample at sufficiently high acidity. The selectivity of the resin over calcium is particularly noteworthy. In fact, calcium concentrations of up to $0.5 \mathrm{M}$ do not appreciably decrease strontium sorption. Also noteworthy is the significant decrease in strontium retention as the nitric acid content of the mobile phase is reduced. Thus, sorbed strontium can be recovered simply by rinsing the resin with dilute acid or water. The ability to recover strontium in water simplifies subsequent processing and analysis of the sample and minimizes waste generation. Table I summarizes the elution behavior of 35 elements on the $\mathrm{Sr}$ resin. As shown, most of the elements, many of which are common constituents of environmental, biological, or geological samples, are essentially unretained by the resin. Only lead is retained as well as strontium.

As is the case for strontium, the development of EXC methods for ${ }^{241} \mathrm{Am}$ separation and preconcentration is complicated by the high concentrations of mineral acids often present in samples, either as a result of pretreatment steps (e.g., soil leaching) or the nature of the sample itself (e.g., nuclear waste solutions). Moreover, the concentration of most or all other sample constituents generally exceeds that of americium by several orders of magnitude. During the 1960's, several extraction chromatographic procedures for americium separations, particularly from other actinides (41-43) or rare earth elements (44), were described. The separation of Am from complex matrices such as environmental samples, however, involved cumbersome procedures requiring combinations of solvent extraction and ionexchange (45).

By the mid-1970's, efforts to improve available processes for the removal of actinides from acidic nuclear waste solutions demonstrated that tetra- and hexavalent 
actinides could be extracted from wastes containing a wide range of acid concentrations by any of a variety of acidic or neutral organophosphorus reagents. In contrast, trivalent species such as ${ }^{241} \mathrm{Am}$ (III) were far less efficiently extracted. Moreover, the available extractants often showed poor selectivity over other waste constituents, required a salting-out agent to enhance extraction efficiency, or suffered from third phase formation problems (40). In the mid-1980's, work by Horwitz and co-workers on the fundamental chemistry of neutral bifunctional organophosphorus extractants (47) culminated in the development of the TRUEX Process (for

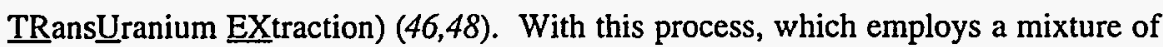
octyl(phenyl)-N, N-diisobutylcarbamoylmethylphosphine oxide (CMPO, Figure 1b) and TBP in a paraffinic hydrocarbon, americium (as well as tetra- and hexavalent actinides) can be efficiently extracted from aqueous solutions containing a wide range (1-6 M) of nitric acid concentrations. In addition, the process exhibits excellent selectivity for actinides over many of the other inert and fission product constituents of typical waste solutions. Subsequent work by two of the authors (MLD and EPH) has shown that TRUEX Process chemistry can provide the basis of a versatile extraction chromatographic material capable of the efficient uptake of ${ }^{241} \mathrm{Am}$ and other transuranium elements from acidic nitrate media $(49,50)$.

Figure 3 shows the nitric acid dependency of the uptake of $\mathrm{Am}(\mathrm{III}), \mathrm{Pu}(\mathrm{IV})$, $\mathrm{Np}(\mathrm{IV}), \mathrm{Th}(\mathrm{IV}), \mathrm{Np}(\mathrm{V})$, and $\mathrm{U}(\mathrm{VI})$ by an EXC resin consisting of a $0.75 \mathrm{M}$ solution of CMPO in TBP sorbed on Amberlite XAD-7. As shown, Am is reasonably well retained from solutions containing 1-6 $\mathrm{M}$ nitric acid. Under these same conditions, few other ions (e.g., lanthanides, $\mathrm{Fe}(\mathrm{III}), \mathrm{Bi}(\mathrm{III})$ ) are appreciably sorbed. In fact, of the common major constituents of environmental and geological samples $(\mathrm{Na}, \mathrm{K}, \mathrm{Ca}$, $\mathrm{Fe}$, and $\mathrm{Al}$ ), only $\mathrm{Fe}(\mathrm{III})$ significantly reduces Am sorption. Reduction of $\mathrm{Fe}(\mathrm{III})$ to $\mathrm{Fe}$ (II) by addition of ascorbic acid, however, eliminates this effect. Since its introduction, the TRU resin (as it has come to be called) has found application in actinide determinations in a variety of complex matrices (51-54). In the course of this work, however, certain limitations of the material have become evident. Americium 
retention, for example, while better than that seen with any previous EXC materials, is still inadequate for certain applications. That is, satisfactory Am separation generally requires acidification of the sample to $\geq 1 \mathrm{M}$ nitric acid. For a large volume sample, (e.g., natural waters) such acidification is not always feasible, as it generates substantial waste. Although this problem can be partly overcome by the use of a larger column, the additional cost makes this an unattractive option.

In the early 1990's, work at Argonne National Laboratory on the use of watersoluble complexants as masking or stripping agents led to the development of a series of substituted methane diphosphonic acid derivatives capable of forming highly stable complexes in acidic media with a variety of metal ions in the tri-, tetra-, and hexavalent oxidation states (55). It has been shown that by replacing two of the four hydrogen ions with an alkyl group, lipophilic dialkyl substituted diphosphonic acids can be prepared which can serve as powerful actinide extractants from highly acidic solutions (56). Work by two of the authors (MLD and EPH) has shown that if an inert polymeric support is impregnated with one such compound, di-(2ethylhexyl)methanediphosphonic acid (Figure 4), abbreviated $\mathrm{H}_{2} \mathrm{DEH}[\mathrm{MDP}]$, an extraction chromatographic resin capable of extraordinarily strong retention of actinides, particularly americium, is obtained (57). Figure 5 shows the acid dependency of $k^{\prime}$ for various actinide species on an EXC resin (now known as Dipex) consisting of $40 \%(\mathrm{w} / \mathrm{w})$ of the undiluted extractant supported on beads of Amberchrom CG-71ms acrylic ester resin. As shown, the retention of all of the actinides is extraordinarily high, a result consistent with prior studies in the liquidliquid mode (56). Especially noteworthy is the strong retention of Am(III): $k^{\prime}{ }_{A m}$ exceeds that obtained using the TRU resin under the same conditions by more than four orders of magnitude. This makes possible the preconcentration of Am from large volume samples using only a small EXC column. Figure 6, for example, shows the effect of the sample volume to bed mass ratio on the uptake of Am by the Dipex resin. As can be seen, Am sorption is quantitative until a ratio of 4000:I is reached, meaning that a $250 \mathrm{mg}$ column would be adequate for the treatment of $1 \mathrm{~L}$ of sample. 
Supports. The extraction chromatography of metal ions, unlike the partition chromatography of organic substances, only infrequently involves the separation of substances with very similar properties. In most instances, an extraction chromatographic column is employed as a "sorption filter" on which the species of interest is retained while others are not (58). Extraction chromatographic separations, therefore, often require only that the sorption of the species of interest be much stronger than that of other sample constituents. Not surprisingly then, the majority of work to improve EXC materials has focused on improved extractants, because it is the extractant that normally governs the selectivity of the system. Despite this, there has been growing awareness of the potential importance of the physical and chemical properties of the support in determining certain aspects of the effectiveness of an EXC system.

A variety of different materials have been employed as EXC supports, among them cellulose, silica gel, diatomaceous earth, alumina, and a variety of polymers (e.g., polyethylene, polytetrafluoroethylene) (58). Several of these (e.g., silica) are generally considered unsuitable for use without preliminary treatment to render their surface hydrophobic and to reduce or eliminate functionalities capable of ionexchange. In the early 1970's, Warshawsky (59) noted the advantages offered by a then new series of macroporous, high surface area styrene-divinylbenzene- and acrylic ester-based polymers (marketed by Rohm and Haas under the designation "XAD") as EXC supports. These supports display good wettability by most extractants, do not swell appreciably as the solution composition changes, exhibit good mechanical stability, and are relatively inexpensive. As a result, most recent research activity in extraction chromatography, including the little work directly concerning the influence of support properties on EXC performance, has involved these and other related polymeric materials impregnated with various extractants. (Note that although extractant-impregnated polymers have been referred to as "solvent impregnated resins", there does not appear to be any compelling reason why 
these materials should be distinguished from other extraction chromatographic materials.) Parrish (60) compared the sorption of copper ions by a series of XAD resins impregnated with Kelex 100, a commercially available chelating extractant based on a high molecular weight derivative of 8-hydroxyquinoline, to that observed for similarly impregnated silanized and unsilanized silica gel and diatomaceous earth. The rate of copper uptake on the XAD resins was somewhat slower, although differences in particle sizes and loading levels among the resins made strict comparisons difficult. The XAD resins, however, offered the advantage of not requiring silanization prior to use. Parrish noted that the rate of copper sorption did not correlate with either the specific surface area or the average pore diameter of the resins. Instead, this rate was found to increase with increasing water regain by the resin. These results appear to contradict those of a previous study of the effect of support geometry on the uptake of europium by HDEHP-loaded silica, which showed that the europium distribution coefficients, the total capacity of the resin for europium, and the kinetics of europium uptake were functions of median pore diameter and pore size distribution $(61,62)$. Recent work by Jerabek et al. (63) suggests that the uptake of certain species (e.g., methanol) is indeed affected by the support morphology (e.g., pore size distribution) for XAD resins, but the relationship of these observations to the performance of the extractant-loaded resins as metal ion sorbents has yet to be determined. Additional work in this area is clearly warranted.

As already noted, an extraction chromatographic support is typically chosen to function as an inert "reservoir" which can be filled to the desired capacity with an extractant. A few studies, however, have described the use of an "active support", defined here as a substrate which interacts with the extractant through other than the weak adsorptive forces typical of EXC materials or one that actually participates in the metal ion uptake process. Several authors, for example, have examined the metal ion sorption properties of EXC materials prepared by impregnating an anionexchange resin with an extractant containing an anionic functional group (64-7I). Tanaka et al. $(65,67-69)$ evaluated a series of resins in which the sulfonic acid 
derivative of dithizone (65), thiopyrine (azothiopyrine sulfonic acid, ATPS) (67), or tetraphenylporphine (68) was sorbed on Amberlite IRA-400, an anion-exchange resin. Similarly, Lee et al. (60) evaluated a resin consisting of Dowex 1-X8 impregnated with a sulfonated 8-quinolinol derivative. Subsequent work by Sarzanini et al. (70) employed pyrocatechol violet, a chelating agent whose structure contains a sulfonic acid functional group not involved in metal ion coordination, sorbed on AG MP-1, a macroporous anion-exchange resin. In each of these studies, the extractants were found to be strongly bound by the ion-exchange resin, most likely by a combination of simple physical sorption and ion-exchange. For ATPS on IRA-400, this sorption was sufficiently strong that the extractant was retained even in the presence of $0.5-1$ $\mathrm{M} \mathrm{HCl}$ or $1 \mathrm{M} \mathrm{NaOH}$ (using a volume:mass ratio of 100:1). The sorption of the metal ion(s) of interest, mercury $(64,65,67-69)$, aluminum (70), copper $(64,66,68)$, and lead (66) was generally found to be satisfactory, although there were indications that immobilization reduced the binding ability of certain ligands (70). In addition, the metal ion uptake capacity of certain of the resins was less than that expected from the amount of chelating agent loaded on the support (60). Despite these problems, the use of a support capable of anion-exchange, in conjunction with an extractant bearing an anionic functionality, may represent a step toward significant reduction of extractant loss from EXC materials.

Moyer et al. (72) have examined the use of cation-exchange resins as supports in extraction chromatography. In their work, a series of polystyrene-divinylbenzenebased cation-exchange resins (among them the commercially available Dowex 50WX8) were impregnated with several weight percent tetrathia-14-crown-4 and the sorption of copper(II) by the resin from sulfuric acid measured. While neither unfunctionalized polystyrene-divinylbenzene resin nor the same resin loaded with the macrocycle extracted any detectable copper, impregnation of the cation-exchanger produced a 10-100-fold enhancement in the observed copper distribution ratio vs. the cation-exchanger alone. This enhancement was attributed to a synergistic effect involving coordination of the copper by the mobile macrocycle and cation-exchange 
by the polymer-bound sulfonic acid functional groups. Although such synergistic effects are common in liquid-liquid extraction systems involving mixtures of crown ethers and liquid cation-exchangers (73), Moyer's results represent the first demonstration of synergism in an EXC material involving a functionalized support. Such supported synergistic systems appear to offer a wealth of opportunities for the development of new EXC materials exhibiting enhanced metal ion uptake and selectivity.

\section{Applications}

The earliest extraction chromatographic materials employed as the stationary phase compounds originally developed for use as liquid-liquid extractants in the reprocessing of spent nuclear fuel (7). Not surprisingly then, until relatively recently, the major portion of the published applications of EXC involved nuclear/radioactive materials, particularly their small-scale separation and purification or analytical determination. During the last decade or so, there has been growing interest in the nonnuclear applications of extraction chromatography and in the possible use of the technique for industrial-scale metal ion separations. Of particular interest has been the potential of EXC in the recovery and/or purification of metals which are valuable (e.g., gold) or of some strategic importance (e.g., rare earths, platinum group metals) from both dilute solutions (e.g., dump leaching solutions) and the more concentrated solutions arising from hydrometallurgical processing. Also of interest has been the possible application of EXC materials in the removal of hazardous or toxic metals from industrial effluents (G). Table II summarizes much of this research activity in process-scale extraction chromatography. As can be seen, a variety of both supports and extractants have been investigated in an effort to develop large-scale EXC systems. Despite some success, these systems have typically been plagued by one major problem: the leakage of extractant into the column effluent and the concomitant changes in column behavior. In an examination of TBP-Levextrel resin for the 
removal of uranium from nuclear reprocessing solutions, for example, Krochbel and Meyer (8) observed a loss of $0.163 \mathrm{~g}$ of TBP per liter of solution processed, an unacceptably high loss. Similarly, in an evaluation of zinc removal from cobalt solutions by HDEHP on XAD-7 or Levextrel OC1026, Warshawsky (74) noted that the low concentration of HDEHP leaking into the column effluent created difficulty in subsequent electrowinning. A study of copper removal from dilute solution using LIX-64N-impregnated XAD-4 yielded similar results. Reagent losses, although low ( $\leq 30 \mathrm{mg} / \mathrm{L}$ processed), were still deemed unacceptable. Given the weak interaction between extractant and support characteristic of EXC systems, extractant loss in these systems is not surprising. Until extractant losses are reduced, however, EXC is unlikely to achieve its full potential as a process-scale metal ion separation technique.

\section{Conclusions}

Extraction chromatography provides a simple and effective means of performing a wide variety of metal ion separations. Recent advances in extractant design, in particular the development of extractants capable of metal ion recognition or of strong complex formation even in acidic media, have substantially improved the utility of the method. Advances in support design, most notably the introduction of functionalized ("active") supports to enhance metal ion retention or to increase column stability, promise to yield further improvements.

Any efforts to improve extraction chromatographic materials must recognize that there are a number of measures by which EXC performance is assessed, some of which cannot be simultaneously improved. Gradual loss of column capacity due to extractant loss to the mobile phase is presently the sole remaining obstacle to largescale application of EXC materials. Clearly then, stability is the aspect of EXC performance which now most warrants additional research effort. 


\section{Acknowledgments}

This paper is based in part on joint publications with our colleagues in the Chemistry, Chemical Technology, and Environment, Safety, and Health Divisions at Argonne National Laboratory. Their efforts are gratefully acknowledged.

This work was performed under the auspices of the Office of Basic Energy Sciences, Division of Chemical Sciences, U.S. Department of Energy, under contract number W-31-109-ENG-38. 
Literature Cited

(1) Wai, C. M. In Preconcentration Techniques for Trace Elements; Alfassi, J. B., Wai, C. M., Eds.; CRC Press: Boca Raton, FL, 1992; p 101.

(2) Walton, H. F.; Rocklin, R. D. Ion Exchange in Analytical Chemistry; CRC Press: Boca Raton, FL, 1990.

(3) Dietz, M. L.; Horwitz, E. P. LC.GC 1993, 11, 424.

(4) Siekierski, S.; Kotlinska, B. At. Energiya 1959, 7, 160.

(5) Warshawsky, A. In Ion Exchange and Solvent Extraction-A Series of Advances; Marinsky, J. A., Marcus, Y., Eds.; Marcel Dekker: New York, 1981; Vol. 8, p 229.

(6) Cortina, J. L.; Warshawsky, A. In Ion Exchange and Solvent Extraction; Marinsky, J. A., Marcus, Y., Eds.; Marcel Dekker: New York, 1997; Vol. 13, p 195.

(7) Extraction Chromatography; Braun, T.; Ghersini, G., Eds.; Elsevier: New York, 1975.

(8) Krochbel, R.; Meyer, A. In Proceedings of the International Solvent Extraction Conference-1974; Society of Chemical Industry: 1974; p 2095.

(9) Kauczor, H. U.; Meyer, A. Hydrometallurgy 1978, 3, 65.

(10) Poinescu, I.; Popescu, V.; Carpov, A. Angew. Makromol. Chem. 1985, 135, 21.

(11) Cortina, J. L.; Miralles, N.; Aguilar, M.; Sastre, A. M. Solvent Extr. Ion Exch. $1994,12,349$.

(12) Cortina, J. L.; Miralles, N.; Aguilar, M.; Sastre, A. M. Solvent Extr. Ion Exch. 1994, 12,371 .

(13) Cortina, J. L.; Miralles, N.; Aguilar, M.; Warshawsky, A. React. Funct. Polymers 1995, 27, 61 .

(14) Cote, G.; Laupretre, F.; Chessagnard, C. React. Polymers 1987, 5, 141.

(15) Bokobza, L.; Cote, G. Polyhedron 1985, 4, 1499. 
(16) Kimura, T. J. Radioanal. Nucl. Chem. 1990, 141, 295.

(17) Miralles, N.; Sastre, A. M.; Aguilar, M.; Cox, M. Solvent Extr. Ion Exch. $1992,10,51$.

(18) Sastre, A. M.; Muhammed, M. Hydrometallurgy 1984, 12, 177.

(19) Sastre, A. M.; Miralles, N.; Aguilar, M. Chem. Scripta 1984, 24, 44.

(20) Casas, I.; Miralles, N.; Sastre, A. M.; Aguilar, M. Polyhedron 1989, 8, 2535.

(21) Casas, I.; Miralles, N.; Sastre, A. M.; Aguilar, M. Polyhedron 1986, 5, 2039.

(22) Strikovsky, A. G.; Jerabek, K.; Cortina, J. L.; Sastre, A. M.; Warshawsky, A. React. Funct. Polymers 1996, 28, 149.

(23) Azaka, I. In Extraction Chromatography; Braun, T., Ghersini, G., Eds.; Elsevier: New York, 1975; p 17.

(24) Ghersini, G. In Extraction Chromatography; Braun, T., Ghersini, G., Eds.; Elsevier: New York, 1975; p 68.

(25) Horwitz, E.P.; Bloomquist, C.A.A. J. Inorg. Nucl. Chem. 1972, 34, 3851.

(26) Hiraoka, M. Crown Compounds: Their Characteristics and Applications; Elsevier: New York, 1982.

(27) Gokel, G. Crown Ethers and Cryptands; Royal Society of Chemistry: Cambridge, England, 1991.

(28) Gutsche, C. D. Calixarenes; Royal Society of Chemistry: Cambridge, England, 1989.

(29) Veselsky, J. C. Mikrochim. Acta 1978, 1, 79.

(30) Juznick, K.; Korun, M. J. Radioanal. Nucl. Chem. Lett . 1989, 137, 235.

(31) Akaza, I. Bull. Chem. Soc. Jpn. 1966, 39, 980.

(32) Lieser, K. H.; Bernhard, H. Z. Anal. Chim. 1966, 219,

(33) Akaza, I.; Tajima, T.; Keba, T. Bull. Chem. Soc. Jpn. 1973, 46, 1199.

(34) Lada, W. A.; Smulek, U. Radiochem. Radioanal. Lett. 1978, 34, 41.

(35) Horwitz, E. P.; Dietz, M. L.; Fisher, D. E. Anal. Chem. 1991, 63, 522.

(36) Horwitz, E. P.; Chiarizia, R.; Dietz, M. L. Solvent Extr. Ion Exch. 1992, 10, 313. 
(37) Chiarizia, R.; Horwitz, E. P.; Dietz, M. L. Solvent Extr. Ion Exch. 1992, 10, 337.

(38) Horwitz, E. P.; Dietz, M. L.; Fisher, D. E. Solvent Extr. Ion Exch. 1990, 8, 199.

(39) Horwitz, E. P.; Dietz, M. L.; Fisher, D. E. Solvent Extr. Ion Exch. 1990, 8, 557.

(40) Horwitz, E. P.; Dietz, M. L.; Fisher, D. E. Solvent Extr. Ion Exch. 1991, 9, 1.

(41) Moore, F. L. Anal. Chem. 1968, 40, 2130.

(42) Horwitz, E. P.; Bloomquist, C. A. A.; Orlandini, K. A.; Henderson, D. J. Radiochim. Acta 1967, 8, 127.

(43) Horwitz, E. P.; Bloomquist, C. A. A.; Henderson, D. J.; Nelson, D. E. J. Inorg. Nucl. Chem. 1969, 31, 3255.

(44) Barbano, P. G.; Rigali, L. J. Chromatogr. 1967, 29, 309.

(45) Ham, G. J. Sci. Tot. Environ. 1995, 173-174, 19.

(46) Horwitz, E. P.; Kalina, D. G.; Diamond, H.; Vandegrift, G. F.; Schulz, W. W. Solvent Extr. Ion Exch. 1985, 3, 75.

(47) Horwitz, E. P.; Diamond, H.; Kalina, D. G. In Plutonium Chemistry; Carnall, W. T., Choppin, G. R., Eds.; American Chemical Society: Washington, D.C., 1983; p 433.

(48) Schulz, W. W.; Horwitz, E. P. Sep. Sci. Technol. 1988, 23, 1191.

(49) Horwitz, E. P.; Dietz, M. L.; Nelson, D. M.; LaRosa, J. J.; Fairman, W. D. Anal. Chim. Acta 1990, 238, 263.

(50) Horwitz, E. P.; Chiarizia, R.; Dietz, M. L.; Diamond, H.; Nelson, D. M. Anal. Chim. Acta 1993, 281, 361.

(51) Kaye, J. H.; Strebin, R. S.; Ou, R. D. J. Radioanal. Nucl. Chem. 1995, 194, 191.

(52) Crain, J. S.; Smith, L. L.; Yaeger, J. S.; Alvarado, J. A. J. Radioanal. Nucl. Chem. 1995, 194, 133. 
(53) Smith, L. L.; Crain, J. S.; Yaeger, J. S.; Horwitz, E. P.; Diamond, H.; Chiarizia, R. J. Radioanal. Nucl. Chem. 1995, 194, 151.

(54) Goldstein, S. J.; Hensley, C. A.; Armenta, C. A.; Peters, R. J. Anal. Chem. 1997, 69, 809.

(55) Horwitz, E. P.; Diamond, H.; Gatrone, R. C.; Nash, K. L.; Rickert, P. G. In Solvent Extraction 1990; Sekine, T., Ed.; Elsevier: New York, 1992; p 357.

(56) Chiarizia, R.; Horwitz, E. P.; Rickert, P. G.; Herlinger, A. W. Solvent Extr. Ion Exch. 1996, 14, 773.

(57) Horwitz, E. P.; Chiarizia, R.; Dietz, M. L. React. Funct. Polymers 1997, 33, 25.

(58) Katykhin, G. S. In Extraction Chromatography; Braun, T., Ghersini, G., Eds.; Elsevier: New York, 1975; p 134.

(59) Warshawsky, A. Inst. Min. Metall., Trans., Sect. C 1974, 83, C101.

(60) Parrish, J. R. Anal. Chem. 1977, 49, 1189.

(61) Nolte, R. F.; Specht, S.; Born, H. J. J. Chromatogr. 1975, 110, 239.

(62) Specht, S.; Nolte, R. F.; Born, H. J. J. Chromatogr. 1975, 110, 253 :

(63) Jerabek, K.; Hankova, L.; Strikovsky, A. G.; Warshawsky, A. React. Funct. Polymers 1996, 28, 201.

(64) Akaiwa, H.; Kawamoto, H.; Nakata, N.; Ozeki, Y. Chem. Lett. 1975, 10, 1049.

(65) Tanaka, H.; Chikuma, M.; Harada, A.; Ueda, T.; Yube, S. Talanta 1976, 23 , 489.

(66) Lee, K. S.; Lee, W.; Lee, D. W. Anal. Chem. 1978, 50, 255.

(67) Chikuma, M.; Nakayama, M.; Tanaka, T.; Tanaka, H. Talanta 1979, 26, 911.

(68) Chikuma, M.; Nakayama, M.; Itoh, T.; Tanaka, H.; Itoh, K. Talanta 1980, 27, 807.

(69) Nakayama, M.; Chikuma, M.; Tanaka, H.; Tanaka, T. Talanta 1982, 29, 503.

(70) Sarzanini, C.; Mentasti, E.; Porta, V.; Gennaro, M. C. Anal. Chèm. 1987, 59, 484. 
(71) Warshawsky, A.; Strikovsky, A. G.; Jerabek, K.; Cortina, J. L. Solvent Extr. Ion Exch. 1997, 15, 259.

(72) Moyer, B. A.; Case, G. N.; Alexandratos, S. D.; Kriger, A. A. Anal. Chem. 1993, 65, 3389.

(73) McDowell, W. J. Sep. Sci. Technol. 1988, 23, 1251.

(74) Warshawsky, A.; Kalir, R.; Berkovitz, H. Inst. Min. Metall. Trans., Sect. C $1979,88,31$.

(75) Warshawsky, A.; Berkovitz, H. Inst. Min. Metall. Trans., Sect. C 1979, 88, 36.

(76) Madic, C.; Kertesz, C.; Sontag, R.; Koehly, G. Sep. Sci. Technol. 1980, 15, 745 .

(77) Kim, T. K.; McClintic, R. P. "Process for Recovering Scandium from Waste Material"; U.S. Patent 4,751,061; 1988.

(78) Barney, G. S.; Cowan, R. G. In Chemical Pretreatment of Nuclear Waste for Disposal; Schulz, W. W., Horwitz, E. P., Eds.; Plenum Press: New York, $1995 ;$ p 51.

(79) Eschrich, H.; Ochsenfeld, W. Sep. Sci. Technol. 1980, 15, 697. 
Table I. Elution Behavior of Selected Elements on the SroSpecific

Chromatographic Resin ${ }^{\mathrm{a}}$

\begin{tabular}{cc}
\hline Elution Volume & Element \\
\hline$<5$ & $\mathrm{Li}, \mathrm{Na}, \mathrm{Rb}, \mathrm{Cs}, \mathrm{Mg}, \mathrm{Ca}, \mathrm{Al}, \mathrm{Cr}(\mathrm{VI}), \mathrm{Mn}(\mathrm{II})$, \\
& $\mathrm{Fe}(\mathrm{III}), \mathrm{Co}(\mathrm{II}), \mathrm{Rh}(\mathrm{III}), \mathrm{Pd}(\mathrm{II}), \mathrm{Cd}, \mathrm{La}, \mathrm{Eu}$, \\
$\mathrm{K}, \mathrm{Ra}, \mathrm{Tc}(\mathrm{VII}), \mathrm{Ag}$ & $\mathrm{Mo}(\mathrm{VI})$ \\
$<20$ & $\mathrm{Ba}$ \\
$<25$ & $\mathrm{Hg}$ \\
$>30$ & $\mathrm{Sr}, \mathrm{Pb}$ \\
\hline${ }^{\mathrm{a} C o l u m n}$ parameters: resin particle diameter $=50-100 \mu \mathrm{m} ;$ bed volume $=1 \mathrm{~mL} ;$ bed height $=5.0$ \\
$\mathrm{~cm} ; 1$ free column volume $=0.60 \mathrm{~mL}$. \\
belution volume refers to the number of free column volumes required to elute $\approx 99 \%$ of the \\
indicated element. The eluent was $3 \mathrm{M}$ nitric acid $/ 0.01 \mathrm{M}$ oxalic acid.
\end{tabular}


Table II. Extraction Chromatographic Systems Evaluated for Possible Process-Scale Application

\begin{tabular}{|c|c|c|c|c|}
\hline Target Ion & Matrix & Extractant/Support & Comments & Reference \\
\hline U & $\begin{array}{l}\text { Leachate of slimes remaining from } \\
\text { Au extraction }\end{array}$ & $\begin{array}{l}\text { Alamine- } 336 \text { on silicone-treated fine } \\
\text { clay }\end{array}$ & $\begin{array}{l}\text { Extractant loss of } 7.1 \mathrm{mg} / \mathrm{kg} \text { resin } / \mathrm{L} \\
\text { processed }\end{array}$ & (5) \\
\hline $\mathrm{Au}$ & Dilute cyanide solutions & $\begin{array}{l}\text { Trialkylammonium compounds in } \\
\text { decyl alcohol/kerosene on } \\
\text { granulated polyethylene }\end{array}$ & $8 \mathrm{mg} / \mathrm{L}$ bed capacity & (5) \\
\hline U & Reprocessing solutions & TBP-Levextrel & $\begin{array}{l}\text { Extractant loss of } 0.163 \mathrm{~g} \text { TBP/L } \\
\text { processed }\end{array}$ & $(8,79)$ \\
\hline $\mathrm{Zn}$ & Co electrowinning solution & HDEHP on XAD-4 & $\begin{array}{l}\text { Reagent leakage interferes with } \\
\text { electrowinning }\end{array}$ & (74) \\
\hline $\mathrm{Cu}$ & $\begin{array}{l}\text { Dilute solution containing divalent } \\
\text { and trivalent cations }\end{array}$ & LLX-64N on XAD-4 & $\begin{array}{l}\text { Extractant loss of ca. } 30 \mathrm{mg} / \mathrm{L} \\
\text { processed }\end{array}$ & (75) \\
\hline Am & $\begin{array}{l}\text { Waste solutions from nuclear fuel } \\
\text { reprocessing }\end{array}$ & $\begin{array}{l}\text { di- } n \text {-hexyl-octoxymethyl phosphine } \\
\text { oxide }\end{array}$ & - & (76) \\
\hline Sc & Sc-bearing waste solutions & HDEHP on polystyrene & - & $(77)$ \\
\hline $\mathrm{Am}, \mathrm{Pu}, \mathrm{U}$ & $\begin{array}{l}\text { Acidic nuclear waste solutions } \\
\text { (Hanford) }\end{array}$ & $\begin{array}{l}\text { CMPO-TBP, CMPO alone, and } \\
\text { diamyl amyl phosphonate on } \\
\text { Amberlite XAD-7 or XAD-16 }\end{array}$ & $\begin{array}{l}\text { Little change in CMPO-TBP column } \\
\text { performance noted after } 36 \text { cycles }\end{array}$ & (78) \\
\hline
\end{tabular}




\section{Figure Captions}

Figure 1. a. Bis-4,4'(5')-[tert-butylcyclohexano]-18-crown-6.

b. Octyl(phenyl)-N, N-diisobutylcarbamoylmethylphosphine oxide.

Figure 2. Nitric acid dependency of the retention of alkali and alkaline earth elements on the strontium selective resin. (Adapted from ref. 3.)

Figure 3. Nitric acid dependency of the retention of actinides on the TRU resin. (Adapted from ref. 3.)

Figure 4. Di-(2-ethylhexyl)methanediphosphonic acid ( $\left.\mathrm{H}_{2} \mathrm{DEH}[\mathrm{MDP}]\right)$.

Figure 5. Nitric acid dependency of actinide retention on the Dipex ${ }^{\top M}$ resin. (Adapted from ref. 57.)

Figure 6. Effect of sample volume to resin mass ratio on the uptake of Am(III) by Dipex ${ }^{T M}$ resin from Des Plaines River water. (Adapted from ref. 57.) 


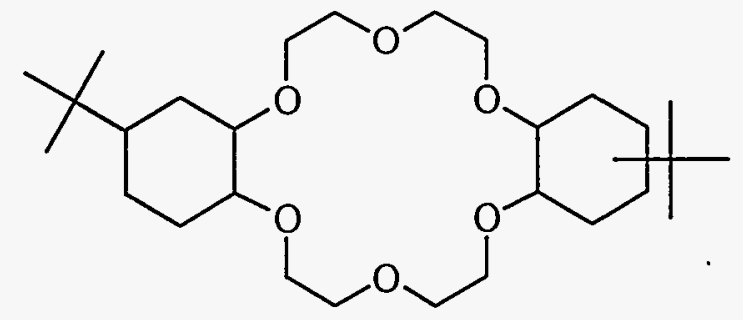

$1 a$

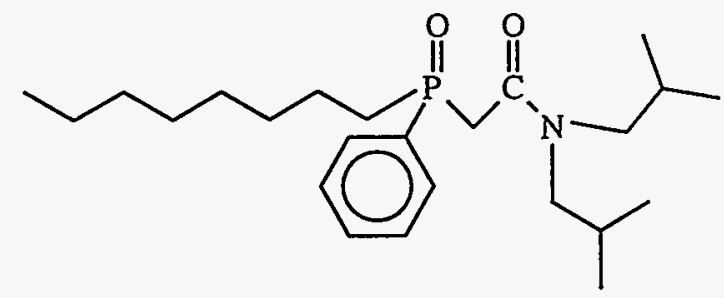

$1 b$ 

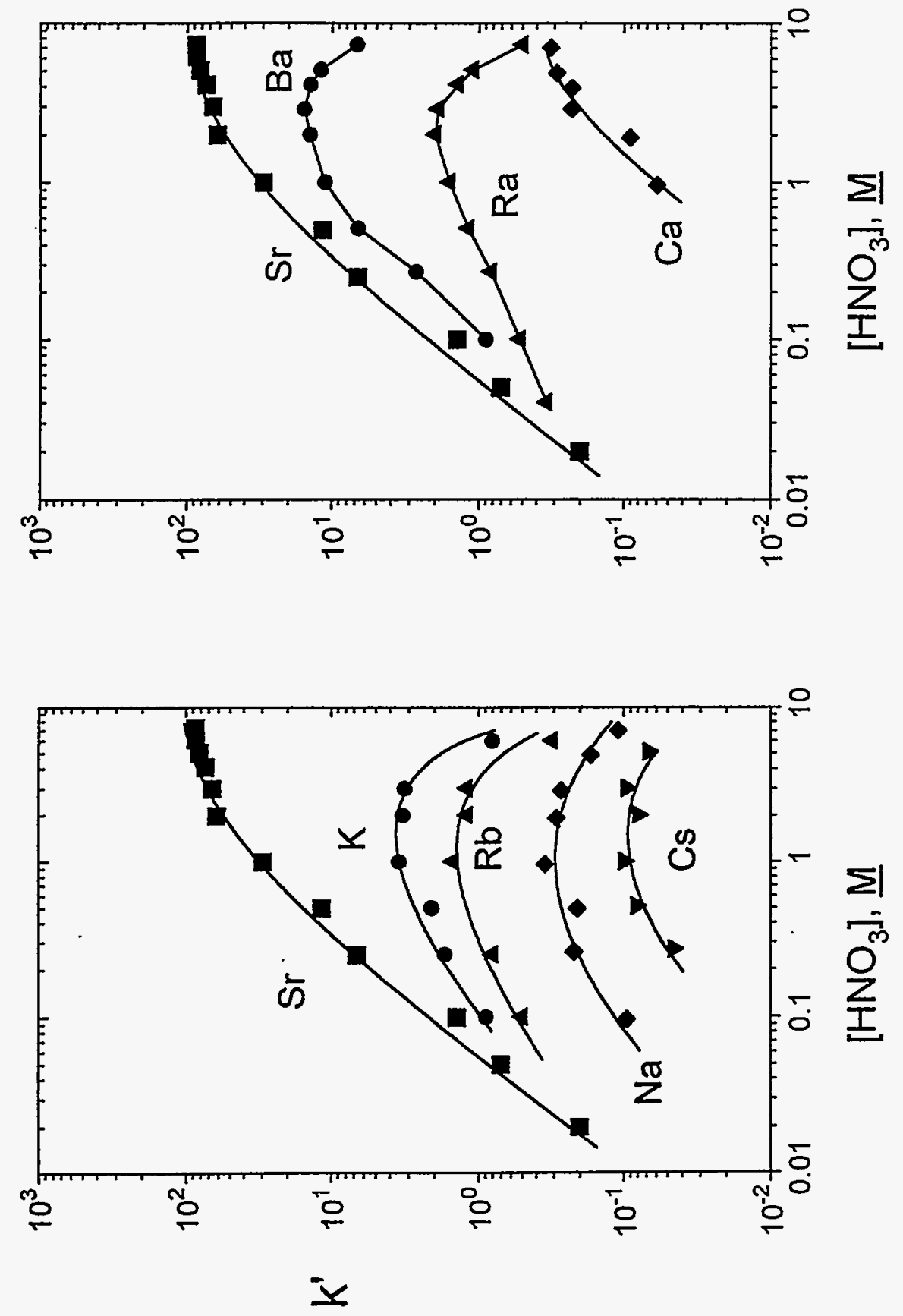


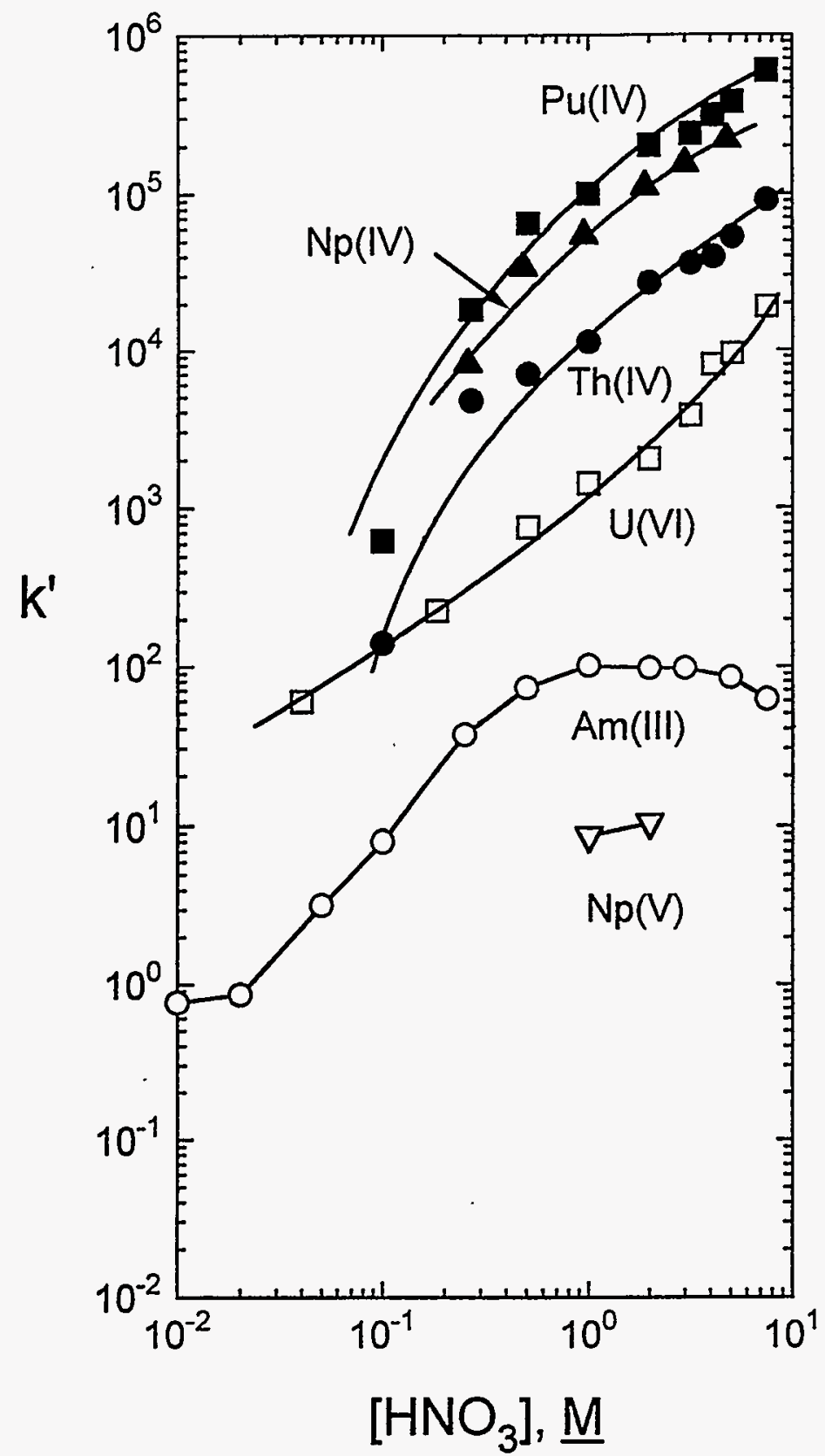




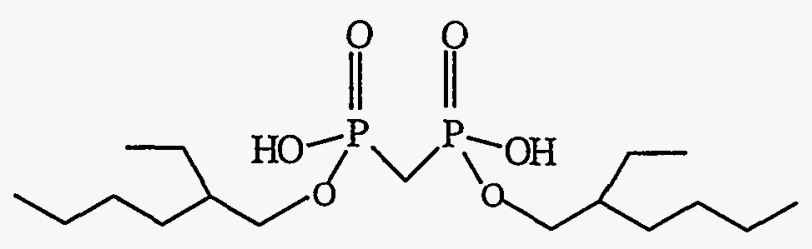

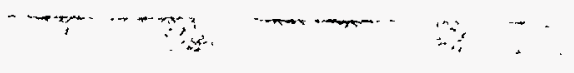




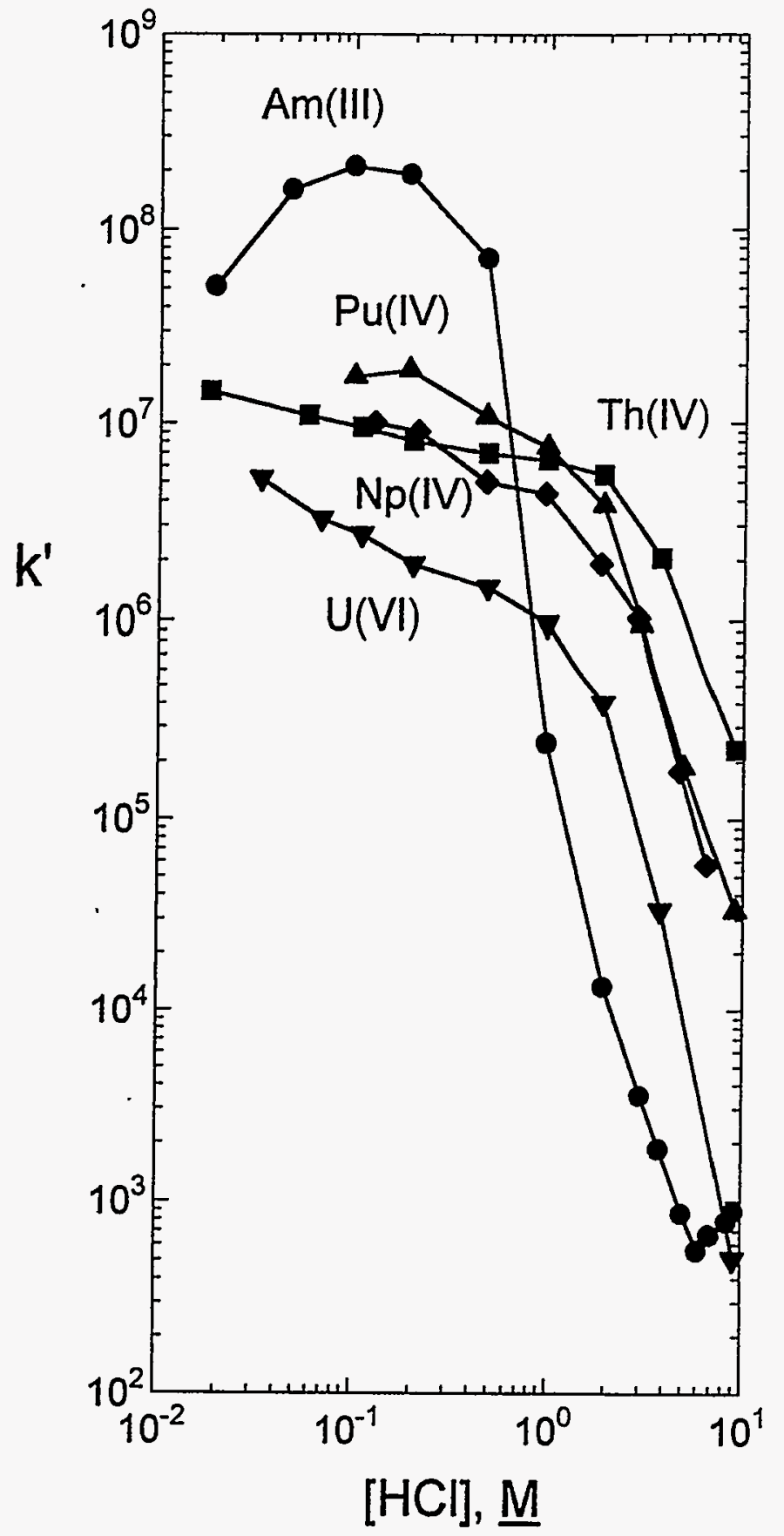




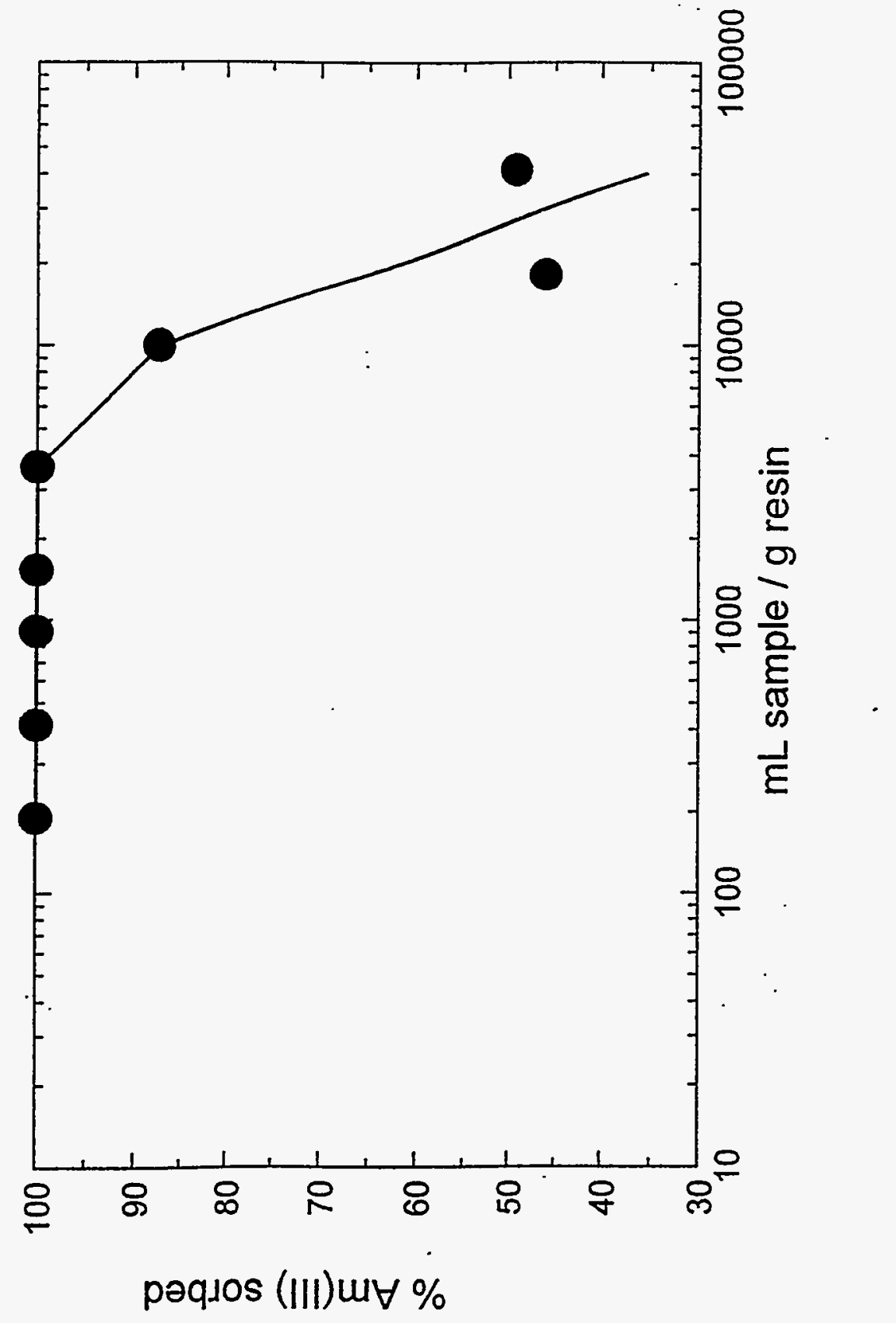

